Trabajos y Comunicaciones, 2da. Época, No 45, e031, marzo 2017. ISSN 2346-8971

Universidad Nacional de La Plata.

Facultad de Humanidades y Ciencias de la Educación.

Departamento de Historia

\title{
Regular la cultura: la intervención de la policía en las prácticas musicales (Buenos Aires, 1820-1833)
}

\author{
Regulate the culture: the police intervention in musical practices \\ (Buenos Aires, 1820-1833)
}

\section{Guillermina Guillamon *}

* Universidad Nacional de Tres de Febrero - CONICET, Argentina | guillermina.guillamon@gmail.com

\section{PALABRAS CLAVE}

Cultura musical

Policía

Teatro

Costumbres y hábitos

KEYWORDS

Musical culture

Police

Theatre

Costumbs and habits

\section{RESUMEN}

El objetivo general del trabajo reside en analizar cuáles fueron las principales áreas de intervención de la policía respecto de la cultura musical. Derivado de ello se indaga en el accionar de músicos, empresarios y funcionarios del estado provincial al momento de reclamar, regular y normar actividades, contratos y espacios materiales a través de la policía. Luego, se aborda aquello que se enunció en las actas tanto como parte del "orden deseable" respecto de actividades y prácticas musicales, costumbres y hábitos del público asiduo al teatro Coliseo Provisional y obligaciones y derechos de asentista, músicos y gobierno. 


\section{Introducción:}

La cultura musical fue durante la primera mitad del siglo XIX una de las esferas artísticas más

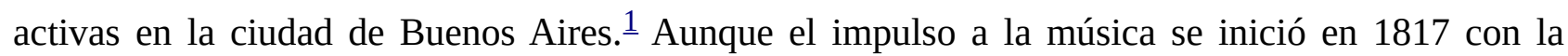
creación de la Sociedad del Buen Gusto por el Teatro fue durante la denominada "feliz experiencia" cuando se sistematizó en la prensa periódica la promoción y crítica de diversas actividades y espacios musicales. En consecuencia, la década de 1820 se caracterizó por la consolidación de espacios de ejecución y educación musical, el posicionamiento socio-profesional de instrumentistas y cantantes y, por sobre todo, la configuración de una programación estrechamente vinculada a la ópera buffa italiana en detrimento de los géneros líricos españoles.

Las convicciones de impulsar y promocionar la cultura musical tuvieron como objetivo transformar las costumbres y prácticas que, según consideraron tanto los gobiernos como las elites letradas, estaban ancladas en un pasado caracterizado por el atraso estético y la subordinación política. En este sentido, sostuvieron que el buen gusto en las artes y la asistencia a espacios ligados a prácticas culturales contribuirían al progreso de la "moral" y del "bienestar" del individuo. Derivado de ello, la música fue considerada -conjuntamente con las representaciones teatrales- como una práctica social y artística, tanto privada como pública, fundamental para superar los vestigios del Antiguo Régimen e instaurar nuevas pautas de civilidad y de interacción social de propias de regímenes políticos modernos.

En este sentido, la prensa fue la encargada de promocionar las actividades musicales, reseñar las diversas funciones líricas e incentivar la afición del público. Principalmente El Argos de Buenos Aires y The British Packet and Argentine News y, en menor medida, El Teatro de la Opinión, El Centinela, El Argentino, La Gazeta y El Americano, fueron aquellos diarios que dedicaron varias secciones a la propaganda musical. En el afán por erigirse como verdaderos connoisseur, su crítica se basó en los supuestos estéticos del paradigma ilustrado antes que en la apreciación y crítica de la ejecución instrumental y vocal. El fin último de las actividades musical era didáctico: la sociabilidad y los juicios de buen gusto que la música habilitaba ayudarían a que Buenos Aires se alejara del pasado caracterizado por la subordinación, el atraso y la lucha facciosa.

Otro plano de acción discursiva y pragmática -escasamente visitado para abordar prácticas culturales- lo constituyó el Departamento General de Policía. $\underline{2}$ Inaugurado como consecuencia de las reformas rivadavianas en 1821, formó parte de una agenda que buscó concretar un orden institucional estable, legítimo y moderno. Si bien sus actas evidencian el énfasis puesto en la seguridad y el control del espacio público, varias de ellas dan cuenta de la intervención en el ámbito de la cultura musical. En última instancia muestran que el concepto de policía condensaba dos acepciones: por un lado, aquella que refería al control y ordenamiento del espacio y, por otro, la que hacía énfasis en la regulación de las costumbres.

Así, las actas de policía permiten iluminar sobre espacios, músicos y programación al tiempo que invitan a reflexionar en torno al orden deseado por el gobierno provincial. En consecuencia, el objetivo general del trabajo reside en analizar cuáles fueron las principales áreas de intervención de la policía respecto de la cultura musical. Derivado de ello se busca problematizar sobre aquellas prácticas musicales que fueron normadas y legisladas, tanto por interés de la propia policía como del gobierno y músicos y empresarios. Por otra parte, se pretende indagar en torno al rol de la 
policía respecto de los intereses privados, dado que en variadas oportunidades ejecutó contratos a arrendatarios y músicos particulares.

Para ello se trabajará, principalmente, con las actas ejecutadas por el Departamento General de Policía durante el período 1820- 1834. Asimismo, el corpus documental se conformará, también, con registros oficiales, prensa de la época, memorias y crónicas diplomáticas. El fundamento del recorte reside en la posibilidad de ver una continuidad en el accionar de la policía respecto de lo musical que excede a la denominada "feliz experiencia”. Si bien las actas decrecieron progresivamente, tanto en la gobernación de Dorrego como de Rosas, persistió el interés por controlar y normar las prácticas y actividades ligadas al ámbito musical. Estas continuidades invitan a reflexionar en torno a las limitaciones de la historia política para, en el caso particular, abordar la historia cultural.

\section{El Departamento General de Policía: buen gobierno, orden público y civilidad.}

El concepto de buen orden fue desde tiempos coloniales sinónimo de bien común y seguridad pública al tiempo que buen gobierno. A partir de fines del siglo XVIII, la preocupación por contener las transformaciones y garantizar el orden social en una ciudad que comenzaba a expandirse y aumentar demográficamente conllevó la introducción de políticas tendientes a gestionar la administración urbana. Reglamentos, bandos y ordenanzas, reformas en la estructura de las autoridades policiales, la creación e intendencias y la división de la ciudad de los distritos y así como las obras relativas a la infraestructura urbana mostraron que el orden público siempre constituyó una preocupación de las élites dirigentes.

En este sentido, dada la injerencia que tendrá el departamento de Policía en la regulación de las actividades y espacios teatrales y musicales, nos interesa señalar la continuidad en el significado del concepto desde la "Real Ordenanza para el establecimiento e Instrucción de Intendentes de Ejército y Provincia en el Virreinato de Buenos Aires” implementada por Vértiz en 1782 hasta el período aquí estudiado. Particularmente, hacemos referencia a las atribuciones que tenía la "baja policía": orden edilicio, la limpieza e iluminación de las calles, la supervisión de vagabundos, el control de espacios comerciales y de recreación como pulperías, tiendas, juegos y plazas, fiestas y bailes. Por su parte, la alta policía estaba ligada al control de la seguridad pública, particularmente a la vigilancia y sanción de los delitos. De forma conjunta, hacían que policía fuese sinónimo de buen gobierno: indistintamente de las funciones asignadas, todos debían velar por el bien común (Rico, 2008: 22-30).

La Policía como sinónimo de orden y gobierno conllevó una nueva idea de gestionar la ciudad y, con ello, supuso la emergencia de nuevas herramientas de regulación y control. Aunque la creación del Departamento de Policía formó parte de un amplio plan reformista y modernizador impulsado durante la "feliz experiencia", el concepto de policía conservó varias de las características de su carga semántica original propias del período tardocolonial. Si bien se ampliaron sus funciones, es posible advertir continuidades en las diversas acepciones formuladas según los contextos. Particularmente, se evidencia aquella definición que relaciona a la institución y a su accionar con la concreción del orden y la civilidad en el espacio urbano. La búsqueda del buen gobierno fue, así, una constante en el derrotero de la institución desde finales del siglo XVIII hasta la década de 1840. 
Pero fue desde que Buenos Aires aceptó las autonomías provinciales y decidió “cerrar las fronteras a potenciales injerencias que pudieran perturbar la marcha hacia el progreso y la felicidad pública” (Ternavasio, 2014: 75) cuando la acción del gobierno provincial estuvo fuertemente orientada al control del espacio y a la modificación y de las pautas de interacción social. El intento más ambicioso por superar las superposición de poderes, atribuciones y funciones en el ámbito de la policía se realizó al calor de las reformas rivadavianas en 1821. Uno de los principales objetivos de la amplia agenda reformista impulsada durante el gobierno de Martín Rodríguez consistió en suprimir los Cabildos del Rio de la Plata y del Luján. Además de representar los vestigios de un pasado caracterizado por la subordinación a la corona española constituían un obstáculo para centralizar las funciones de Hacienda, Justicia y Policía. $\underline{3}$ Derivado de ello, la creación del Departamento General de Policía en 1821 se insertó en un proceso que buscó concretar dos objetivos fundamentales: modernizar el aparato político y centralizar las estructuras administrativas del estado provincial (Ternavasio, 2000: 172).

En este sentido, la organización y el control del espacio social se enmarcó en un objetivo más amplio, a saber, “civilizar las costumbres” en tanto la configuración de un nuevo trato social entre los otrora súbditos y ahora ciudadanos. En tanto una correcta forma de desenvolverse en la ciudad, la sociabilidad fue considerada "un corolario de la experiencia urbana y al mismo tiempo un requisito y una consecuencia de la vida en la ciudad” (Duhau - Giglia, 2008: 32). Así, todos los ámbitos privados de las elites se transformaron en “(...) objetos de la acción explícita de un Estado que se sentía impelido a moldear costumbres y prácticas que una sociedad civil e imperfecta y parcialmente pulverizada no estaba en condiciones de hacer” (Myers, 2000: 112).

Dos perspectivas historiografías se condensan en este análisis. Por un lado, los trabajos ligados al análisis del derrotero de la ciudad de Buenos Aires, que hacen hincapié en el desarrollo y regularización de la urbanidad, la modificación de los espacios materiales y simbólicos, la instauración de herramientas tendientes al control social así como en la agenda de medidas políticas para ello dispuestas. Por otro, aquellos trabajos que sitúan su análisis en el plano de la sociabilidad política y social. Mientras que los ligados a la historia política enfocan su análisis en las dinámicas de sociabilidad propias del fenómeno asociativo y tienen en Maurice Agulhon su horizonte teórico, otros proponen superar la forma para indagar en la experiencia. En este sentido, es necesario resaltar la propuesta de Sandra Gayol - a la que este trabajo suscribe- para pensar la sociabilidad como una forma de configurar relaciones sociales, en tanto “(...) contactos, relaciones, encuentros intercambios cara a cara y directos gestados entre dos o más personas (...) interacciones sociales que implicaban deberes, derechos, expectativas, supuestos apoyados en valores y en un sistema de creencias" (Gayol, 2000: 15).

En esta misma línea, si el prisma de análisis se centra en el estudio de la dinámica de la vida cultural, el caso de la ciudad de Buenos Aires posee ciertas especificidades que la alejan de la propuesta de Agulhon. Según Paula Bruno “(...) en los territorios que rompieron el lazo colonial con España fueron más frecuentes las superposiciones de formas de asociación y menos claras las definiciones sociales de las mismas” (Bruno, 2014: 9). Así, tanto el solapamiento de instituciones públicas, privadas, asociaciones y logias como la diversidad de grupos sociales que transitaron dichos espacios, complejiza el uso de un marco analítico que piense a las asociaciones como 
instancia sustitutiva de ámbitos ligados al Antiguo Régimen.

Si bien hay prácticas y espacios musicales que excedieron la esfera de acción de la Policía, las actas permiten indagar sobre cuál fue el nivel de intervención del gobierno provincial en torno a la cultura musical al tiempo que analizar las disposiciones normativas - discursivas, en este caso- para regularla. En este sentido, la pertinencia de abordar dicho corpus documental se fundamenta en la posibilidad de mostrar que, si bien músicos y cantantes tuvieron amplia libertad de acción respecto de la configuración de la programación musical, el Departamento de Policía fue el medio a través del cual la esfera política reguló e intervino espacios y prácticas musicales.

Asimismo, dado que muchas de las actas son redactadas a razón del pedido de músicos y empresarios, se puede ver cómo sujetos anclados en la cultura musical, y mayoritariamente inmigrantes italianos y españoles, encontraron en la Policía un intermediario para realizar pedidos al gobierno. ${ }^{4}$ Por último, permiten echar luz sobre algunas incertidumbres respecto de las relaciones entre el poder político y el Teatro Coliseo Provisional, específicamente en la injerencia del Estado provincial sobre un espacio que, si bien se impulsó y se promocionó como órgano difusor de la ilustración, nunca dejó de ser propiedad de particulares.

Las actas pueden dividirse en cuatro grupos diferenciados según el enunciador, el ejecutante o intermediario de la medida y el destinatario. Primero, aquellas que se corresponden con la aplicación de órdenes y disposiciones del gobierno provincial hacia músicos y espacios y que debería aplicar el departamento o jefe de policía. Luego, aquellas que hacen referencia a la intervención de la policía en tanto mediador entre el gobierno y los músicos y empresarios. En la misma línea, también se encuentran las actas que son elevadas por la iniciativa de músicos y empresarios particulares y están dirigidas al gobierno provincial, intervención de la policía mediante. Por último, están aquellas que solamente se componen de destinatario y emisor, específicamente las actas en las cuales la policía contesta a peticiones de músicos particulares.

Más allá de esta posible diferenciación, todas las actas accionan sobre el Teatro Coliseo Provisional y, en menor medida, sobre la Sociedad Filarmónica y están dirigidas normar la actividad de músicos particulares, compañías y empresarios teatrales. Por otra parte, el contenido de las actas fue variado: contestaciones de solicitudes de músicos para dar conciertos, regulaciones y cancelaciones de contratos de arriendo del teatro, creación de reglamentos de policía externa del teatro, regulación de funciones y precios y ordenamientos respecto de la infraestructura del teatro.

A fin de concretar los objetivos previamente expuestos, se decidió dividir el trabajo en dos partes, atendiendo al contenido de las actas. En primer lugar se indagará en el accionar de músicos, empresarios y funcionarios del estado provincial al momento de reclamar, regular y normar actividades, contratos y espacios materiales. En una segunda instancia se pretende abordar aquello que se enunció en las actas tanto como parte del "orden deseable" respecto de actividades y prácticas musicales, costumbres y hábitos del público asiduo al teatro Coliseo Provisional y obligaciones y derechos de asentista, músicos y gobierno. 


\section{Regular, normar, reclamar: los sujetos en acción.}

Analizar el contenido de las actas de policía permite, por un lado, reconstruir el derrotero que atravesaron músicos y empresarios en la búsqueda por convertir la práctica musical en una actividad capaz de generar ganancias. Por otro lado, también invitan a reflexionar sobre el accionar del gobierno y del departamento de Policía en torno a la regulación e implementación de disposiciones relativas a la infraestructura del teatro Coliseo Provisional, precios de funciones extraordinarias y a beneficio, pagos de alquiler y contratos de compañías y asentistas. En este sentido, el presente apartado busca indagar cómo accionaron - reclamando, normando y regulando- músicos, empresarios y funcionarios del estado provincial en tres campos: la intervención en torno al estado edilicio del teatro, la ejecución de contratos y de contratos de arriendo de dicho espacio y la regulación de funciones a beneficio de cantantes y músicos particulares.

Siendo más estable que lo previsto en su nombre, el teatro Coliseo Provisional tiene una historia atravesada por pujas de intereses económicos y políticos, más allá de las funciones propias que todo dispositivo cultural posee. $\underline{6}$ En este sentido, el teatro también constituyó un mecanismos de pedagogía cívica y de control social que, al tiempo que difundía valores republicanos, normaba y censuraba la manera en la que se debía actuar en el espacio público (Gallo, 2005, Molina, 2004). Sin embargo, más allá del énfasis puesto en la representación de las obras teatrales, lo que nos interesa señalar es que, previo al abordaje de las actas de policía, resultaba paradójico el poco interés que el grupo rivadaviano manifestaba por el control de espacio. ${ }^{7}$ Esto se infería también, del hecho de que el teatro había quedado por fuera de su programa de reformas urbanas $\mathrm{y}$, consecuentemente, del nuevo diseño de la ciudad impulsado por Rivadavia.

La única referencia a una futura acción tendiente a reformar su estructura se había insinuado a fines de 1822, ya que se consideraba “(...) más que urgente desplegar nuevos esfuerzos para acordar la consideración que reclama el establecimiento de un teatro en esta capital, que siendo digno de ella, ejerza la influencia que debe tener en la moral y en la decencia pública”. $\underline{8}$ Por ello, a continuación se decretó que "Luego de que sean concluidas las obras del mercado y de la casa de Gobierno, el jefe de Ingenieros dará principio á la conclusión del edificio llamado del Coliseo”. $\underline{9}$

Advirtiendo la necesidad de mejoras, diversos diarios reflexionaron sobre su estado material y, derivado de esta situación, la contradicción que suponía realizar allí actividades consideradas “civilizadas" como la música. $\underline{10}$ El alegato frecuentemente esgrimido fue la necesidad de ostentar un teatro que fuese capaz de demostrar la condición civilizada y de buen gusto de la que sería poseedora Buenos Aires. En consecuencia, debería funcionar tanto como un espacio de distinción social para la elite porteña como un instrumento para asemejar a Buenos Aires a las principales capitales europeas. Así en 1824 El Teatro de la Opinión intervino en el pedido. En una nota enviada por “los amantes del teatro”, se realizó, de forma anónima una fuerte crítica al manejo del asentista, las compañías y la nula intervención del gobierno. La justificación de que la situación debía ser superada se fundamentó en que:

Este establecimiento, que en todos los pueblos civilizados es el barómetro de su cultura, su delicadeza y su moral ha tenido la desgracia en Buenos Aires de pertenecer siempre á empresarios ineptos é incapaces de manejarlo; ó ha estado bajo la férula de la misma compañía, y Dios sabe cual ha sido la mejor. $\underline{11}$ 
Si bien nunca se concretó la reforma del Coliseo, las actas nos permiten ver varios de los derechos y obligaciones que poseía el asentista y el gobierno respecto del teatro. $\underline{12}$ En el caso del mantenimiento de la infraestructura, si bien correspondería al gobierno, luego del fallido proyecto de remodelarlo, las autoridades se excusaron en que los fondos serían destinados a la conclusión del nuevo teatro, proyecto que no se concretó sino hasta 1834. Así, en una nota elevada por el asentista con el fin de pedir dinero para sostener la infraestructura, el gobierno contestó que la policía debía cesar de cobrar el derecho sobre cada función a fin de que con dicho rédito el asentista arreglara la portada del teatro. $\underline{13}$

Meses después, el asentista volvió a consultar sobre si dicha exención era extensiva a las funciones a beneficio de instrumentistas y cantantes, insinuando que este mecanismo devenía en una pérdida en sus intereses económicos particulares. $\underline{14}$ Lo interesante de esta nota es que evidencia la intención del asentista por reglamentar su actividad y obtener un mayor rédito del asiento, aunque respetando los límites impuestos por el gobierno. La contestación reitera que se lo exime de cobrar la cuota que pagaba por función a la policía al tiempo que estaba habilitado para cobrar dicho monto a los beneficiarios a fin de que este dinero sea destinado a mejorar el estado edilicio del teatro. $\underline{15}$

$\mathrm{Al}$ interés por el estado material del teatro, se sumó la regulación de contratos, tanto con el asentista como con el dueño. En este contexto, en agosto de 1824, El Argos de Buenos Aires manifestó que el músico Pablo Rosquellas había iniciado un juicio contra el asentista en el que pedía al gobierno poder alquilar el teatro -específicamente la temporada- a fin de realizar dos funciones mensuales. $\underline{16}$ El juicio contra Antonio Pereyra, el por entonces asentista, según se detalla en el expediente, residió en impugnar un supuesto contrato en el cual Rosquellas se comprometía a efectuar dos funciones mensuales con un sueldo mensual de 200 pesos. No sólo consideró bajo el sueldo propuesto sino que manifestó que no estaba dispuesto a trabajar bajo la dirección de un asentista que no fuese él mismo. De forma paralela, la prensa además de señalar las intenciones de Rosquellas de poder liberarse de las obligaciones contraídas con el asentista, ya había señalado y criticado la falta de funciones líricas. $\underline{17}$

Si bien este juicio no fue descrito explícitamente por las actas, se encuentran irregularidades respecto de los contratos realizados durante 1824. El primero de ellos, fue realizado en mayo de 1824 por voluntad del propio asentista, Antonio Pereyra, a fin de reglar su labor. Compuesto por 12 extensos artículos, el contrato refiere a obligaciones respecto del número de funciones, pagos y contratos a músicos y actores, y, por sobre todo, a las mejoras que debía realizar tanto en lo que refiere a la infraestructura como a la colección de piezas teatrales, de canto y música. $\underline{18}$

Aunque en la contrata de Pereyra se advertía que las obligaciones se extenderían por dieciocho meses, el 17 de septiembre de 1824 Pablo Rosquellas elevó una nota a Rivadavia y manifestó su

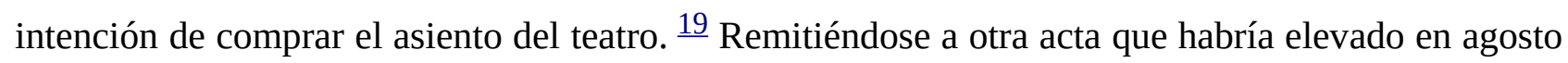
y de la cual no había obtenido respuesta, volvió a reiterar el pedido, acompañado de un largo programa de reformas a efectuarse por la "Sociedad de los Tres Amigos", asociación también compuesta por Julian Moreno y Gabriel Munilla. Si bien no se han encontrado actas relativas a la concreción del asiento, a partir de 1825 la actividad del Coliseo Provisional se caracterizó por llevar 
a adelante una programación sistemáticamente orientada a la ópera bufa, género introducido, principalmente, por Pablo Rosquellas y su compañía lírica. $\underline{20}$

La regulación de precios de entradas fue otra de las esferas de intervención, tanto de la policía como del propio gobierno. Tal como se señaló previamente, fue a inicios de la década de 1820 cuando, bajo el impulso del músico y empresario Pablo Rosquellas, comenzó a promocionarse en diversos diarios la programación de las funciones de música -particularmente arias de ópera- a desarrollarse en el teatro Coliseo Provisional. En ellas se explicitaron las formas que se ejecutarían, los compositores de las mismas al tiempo que advirtieron que éstas se harían a beneficio de algunos de los cantantes o instrumentistas de la compañía. Según Roger Allier (2008: 54-55) este anuncio, originado hacia fines del siglo XVIII europeo, conformó una estrategia a fin de paliar la inseguridad económica de los principales cantantes.

Si bien el sistema de beneficios gozó de popularidad, fue eliminado paulatinamente ya que el hecho de que se realizaran tantas funciones a favor de la compañía terminó por limitar los ingresos de los asentistas del teatro. Sin embargo, las funciones a beneficio permiten inferir tanto la inicial inestabilidad de la compañía como la inexistencia de ayuda económica por parte del Estado provincial. Siguiendo esta perspectiva, su paulatina desaparición -hacia fines de 1828- evidenciaría la consolidación de la compañía y, en consecuencia, la profesionalización de músicos y cantantes.

A diferencia de esto, las actas de policía muestran que el pedido de funciones a beneficio a efectuarse en el Coliseo Provisional finalizó en 1824, momento en el cual se regularon los precios de funciones y de arriendo del teatro al tiempo que se realizó el primer contrato entre el gobierno y un particular, en calidad de asentista-empresario. Pero no sólo en el teatro se realizaron funciones a beneficio. Durante 1823 y 1824 los principales instrumentistas y cantantes realizaron varios pedidos al Gobierno para desarrollar funciones en la Sociedad Filarmónica, espacio ligado a intereses particulares y que de no ser por su reglamento interno, no contaba con ninguna legislación respecto de músicos externos a dicho espacio. $\underline{21}$ Frente a los diversos pedidos realizados, el gobierno terminó por reglamentar que los precios a cobrarse deberían ser los mismos para empresarios que para actores y músicos beneficiarios. $\underline{22}$

La intervención de la policía, pedido del gobierno mediante, para acordar precios y funciones en el teatro tuvo su fin en 1827, dos meses antes de la renuncia de Rivadavia. En el acta, firmada por Santiago de Agüero, se afirma que la intervención se justificaba “cuando se introdujo aquella práctica en un tiempo en que no estaban sancionadas las garantías individuales, ni aquellas en que el Coliseo era una propiedad pública”. $\underline{23}$ Ahora, una vez restaurado el orden y la tranquilidad a la ciudad y normada la actividad teatral, se dejaba a Don José Olaguer Feliú, dueño del teatro, en libertad de disponer los precios a entradas y aposentadurías.

\section{Intervenir para civilizar: la búsqueda del orden en el teatro Coliseo Provisional}

Los pedidos y regulaciones presentes en las actas al tiempo que muestran cómo los sujetos accionaron también describen diversos aspectos de la cultura musical. En este sentido, el presente apartado pretende abordar aquello que se enunció en las actas tanto como parte del "orden 
deseable” respecto de actividades y prácticas musicales, costumbres y hábitos del público asiduo al teatro Coliseo Provisional y obligaciones y derechos de asentista, músicos y gobierno. La información que brindan las actas además de complementar aquella deudora de la prensa del período de diversas actividades musicales, evidencia la intención por parte de la elite letrada siempre indisociable del gobierno- de normar diversas situaciones que trasgredían el ideal de comportamiento esperado por parte del público.

En primer lugar, los contratos de arriendo del teatro de Juan Antonio Pereyra y Pablo Rosquellas refieren a necesidad de dotar de repertorios como de cantantes, músicos y actores al Coliseo Provisional. Si bien este objetivo había formado parte de la agenda de reformas a concretarse por la -efímera- Sociedad del Buen Gusto por el Teatro en 1817, la promoción de obras tuvo un salto cualitativo recién en 1823, momento en el cual Rosquellas arribó a Buenos Aires. Un año después de su llegada, y con el objetivo de lograr el arriendo del teatro, envió una carta a la policía en la cual se comprometía a “(...) surtirlo de piezas selectas, tanto de representado como de música y canturia, vestuario y decoración, haciendo venir a mi costa de otras partes lo que no pudiera conseguirse en el país”. $\underline{24}$

Pero, tal como se comentó previamente, el incumplimiento de sus obligaciones llevó a que Rosquellas fuese el siguiente asentista. En su contrato, afirmó que no omitiría esfuerzo alguno "hasta conseguir su representación en el teatro de Buenos Aires de las grandes composiciones que ya hoy decoran los principales de Europa” $\underline{25}$ y que ya había adelantado fondos a España para obtener, hacia fines de 1825, al menos treinta óperas con su correspondiente música y letras en castellano, francés e inglés. Asimismo, se comprometía a formar en “el decoro y la sutileza” a las cantantes líricas Angela y Maria Tanni, recientemente convocadas por el propio Rosquellas desde Rio de Janeiro y que posteriormente se convertirían en las primas donna de la compañía.

Si bien podría pensarse que la oferta formaba parte de la intención de lograr la contrata, si se indaga en el repertorio que su compañía ofreció en Rio de Janeiro desde 1819 hasta 1823 se verifica que sólo tres de las más de veinte óperas realizadas en Buenos Aires fueron presentadas previamente. $\underline{26}$ Asimismo, la promoción de la programación del Teatro que realizó la prensa es coincidente con el contrato ejecutado con Pablo Rosquellas, en tanto que a partir de 1824 predominaron las óperas bufas al tiempo que desaparecieron la tonadilla y el sainete. Mientras que la ópera estuvo asociada al buen gusto, las formas líricos-teatrales españolas fueron condenadas en la prensa por su nula calidad estética y musical y, por sobre ello, por ser representativas de un pasado ligado subordinación y al atraso.

Otro aspecto que resalta es el referido a las mejoras de la infraestructura del teatro como así también los obstáculos se presentaban en dicho espacio para concretar las funciones. El primer dictamen de las actas refirió a la recomposición de la portada ya que, tal como había indicado la prensa, su estado no se correspondía ni con la intención modernizadora del Estado y, menos aún, con la distinción de las familias que allí asistían. $\underline{27}$ Luego, se agregaría la intención del asentista de hacer un vestíbulo a la calle y reparar las escaleras internas a fin de que el teatro "aparezca con la decencia que le es propia”. $\underline{28}$ 
Tal como la prensa había señalado respecto a la precariedad de la estructura del Coliseo, también se refirió insistentemente a los desórdenes que previa y posteriormente a las funciones ocurrían en la entrada del teatro y a ciertas prácticas y costumbres internas que no eran consideradas de buen gusto. En concordancia con estas interpelaciones, en noviembre de 1824, una vez transferido el asiento del teatro a Rosquellas, se realizó un extenso reglamento con el objetivo de normar las atribuciones que debería tener la policía respecto del orden externo e interno del teatro. $\underline{29}$ El fin último era "la conservación del orden público" mediante la acción de un cuerpo de guardias y celadores que estarían bajo el control de un comisario.

En este sentido, el reglamento dispone cómo debería accionar la policía en relación a prácticas que transgredieran el orden durante las funciones de ópera, música y teatro. Lejos de generalizar el accionar, el reglamento refiere a situaciones concretas, hecho que permite inferir la existencia de prácticas que perturbaban el orden y la tranquilidad deseada para el teatro. $\underline{30}$ Los atributos otorgados al cuerpo de zeladores internos si bien priorizan un accionar "suave y prudente" también los habilita a recurrir al Comisario y realizar el arresto mediante la fuerza.

En cuanto a los posibles impedimentos a la realización de las funciones por razones ajenas a la voluntad del asentista o músicos se señalaron las lluvias, temporales y hasta la posibilidad de un incendio. Esta última advertencia refiere no sólo al peligro que representaba la iluminación mediante velas de cebo sino al antecedente del incendio acaecido en el antiguo teatro, La Ranchería, en 1792. Por esta razón, se reglamentó que a fin de prevenir cualquier accidente "el director del establecimiento tendrá, constantemente, dentro y fuera de la escena, tinas llenas de agua, esponjas y demás útiles correspondientes”. $\underline{31}$

También respecto del orden del Coliseo, el reglamento de la policía del teatro ilumina sobre los espacios internos, particularmente de las distintas divisiones. Por un lado, la policía debía garantizar el ingreso ordenado a la cazuela, los palcos y las platea al tiempo que prohibir el ingreso a toda persona que no tuviese la entrada o abono correspondiente. $\frac{32}{}$ Asimismo, estaba vedada la entrada a cualquier persona que llevase criaturas de pecho y se permitía echar a todo aquel que fumara en los pasillos cuando la luz estaba apagada. $\underline{33}$

La prensa de la época señaló que cada espacio era propio de distintos grupos sociales, específicamente la cazuela o gallinero era el lugar de los sectores bajos mientras que los palcos de las familias de elite. Sin embargo, las crónicas y memorias sobre período enuncian que, por el contrario, en el caso del teatro también estuvieron presentes los sectores bajos de la sociedad. Al respecto de la presencia de otros grupos sociales, Santiago Wilde (1966: 48) indicó que:

La Cazuela vulgarmente llamada aquí el Gallinero (que no tenemos conocimiento que existía en teatro alguno de Europa), estaba colocado más arriba aún que los palcos (...) en efecto, entre las diosas de la cazuela, había gente de todas las capas sociales, pero el modo de portarse era tan ejemplar que hacía honor a nuestras costumbres. Muchas señoras y niñas de familias principales, iban, pues, una que otra vez a la cazuela, cuando no querían vestir como para ocupar un palco. $\underline{34}$

En este mismo sentido, a razón de una consulta elevada por el Departamento de policía a fin de 
establecer la capacidad del teatro, el gobierno advirtió el exceso de gentes de color que concurría a los palcos y que transitaba por los pasillos. Ante esta situación, el acta firmada por Juan Manuel de Rosas advertía que "lo que en agravio del decoro público se espera que sin perjudicar la libertad de que todos asistan procure por los medios posibles la preferencia de la parte más distinguida de la sociedad, evitando así los inconvenientes que puedan resultar de aquel concurso”. $\underline{35}$

\section{A modo de cierre}

La cultura musical constituye una de las áreas temáticas menos frecuentadas por la historiografía argentina. El vacío creado condujo a construir un relato que, anclado en producciones musicológicas de mediados de siglo, sólo se refirió a itinerarios de músicos y estrenos de obras. En este sentido, en instancias previas a este trabajo, la información brindada por prensa del período, escritos teóricos de particulares y crónicas y memorias nos permitió reconstruir las transformaciones en la programación musical - particularmente la construcción de un gusto y afición por la ópera bufa- e indagar en torno al uso discursivo que se realizó del concepto de buen gusto, en tanto ideario normativo para pensar, sentir y actuar en lo que se anunciaba como un nuevo régimen político y cultural.

Sin embargo, poco veíamos sobre la interacción entre músicos, empresarios y funcionarios del poder político. El acceso a las actas del Departamento de Policía al tiempo que complementó el corpus documental permitió iluminar en torno a la intervención del naciente Estado provincial respecto de las actividades musicales. Así, por un lado se indagó en el derrotero que atravesaron músicos, empresarios y cómo éstos reclamaron, regularon y normaron actividades, contratos y espacios materiales. Particularmente, se pudo ver la constante interpelación de los principales músicos al Estado a fin de que éste regulara sus actividades y actuara como mediador respecto de intereses en conflicto. Aunque el número de actas disminuyó a partir de 1833, se puede ver cómo aún una vez finalizada “feliz experiencia”, la policía siguió accionando sobre la cultura musical.

Por otra parte, las actas enuncian el orden deseado respecto de hábitos y costumbres. Las referencias que la policía realizó de situaciones concretas muestran la existencia de prácticas que irrumpieron el orden y la tranquilidad esperada en las funciones musicales en el teatro. Si bien muchos de estos desórdenes eran denunciados en crónicas y memorias, no había registro de la intervención de la policía en dichos espacios. Al tiempo que se enunció el orden esperado, se accionó en pos de reglamentar el funcionamiento ante eventuales irregularidades dentro del teatro.

Por último, este trabajo tuvo el objetivo de poder pensar a la cultura musical como un mundo del arte en donde, además de converger convenciones estéticas, recursos, obras, críticos, músicos y empresarios, el naciente Estado provincial y el poder político también cooperaron para poder crear patrones de acciones colectivas que, durante el período estudiado, tuvieron un carácter sistemático. La idea de "mundo del arte”, deudora de la propuesta de Howard Becker, habilita a pensar que aquellos intereses defendidos por el Estado - tales como la civilidad y buen gusto- a través de la intervención en las artes están en estrecha relación con "la preservación del orden público -se piensa que las artes pueden fortalecer o subvertir el orden- y con el desarrollo de una cultura nacional, que se considera un bien en sí misma y algo que impulsa la unidad nacional ("nuestro 
patrimonio”) y la reputación de la nación entre otras naciones” (Becker, 2008: 212)

Si bien el Estado y sus agentes actúan, siguiendo a Becker, según sus propios intereses, en el caso analizado éstos coincidieron con los objetivos de músicos y empresarios particulares. Así, la intención del poder político de incentivar la cultura musical como parte de un programa ilustrado que buscó modernizar hábitos y costumbres y fomentar la afición y el gusto del público a formas musicales consideradas civilizadas, coincidió con la voluntad de instrumentistas, cantantes y empresarios de consolidarse profesionalmente en una esfera artística que poco impulso había recibido hasta entonces.

\section{Notas}

$\underline{1}$ Cuando en el trabajo utilizamos el concepto de cultura musical, hacemos referencia a términos que fueron operacionalizados y que están constituidos por las siguientes dimensiones: espacios, prácticas, patrones de escucha, redes, compañías líricas, negocios teatrales, circulación de saberes y diversas producciones escritas.

$\underline{2}$ Debe señalarse el antecedente del trabajo de Marcela Aspell (1993). Allí, la autora advierte la contratación de actores y espacios públicos mediante el abordaje de los Protocolos Notariales y los Registros de Policía. Respecto de dicha institución, se señala que al tiempo que tuvo un rol activo en la regulación de la actividad teatral, éste se vio reforzado por la interpelación de los actores que vieron en la Policía una autoridad capaz de reglamentar y regular sus contratos de trabajo.

$\underline{3}$ Previamente a 1821 las autoridades también buscaron concentrar el poder de la policía y concretar una estructura burocrática rentada. Así, en 1812 se creó la Intendencia General de Policía, organizada, a su vez, por el Reglamento Provisional de Policía sancionada en diciembre del mismo año, en donde se contemplan sus atribuciones y obligaciones. El intendente tuvo, siguiendo a Galeano, una doble jurisdicción pero también una doble limitación: por un lado, sería el encargado de mantener la limpieza y administración de la ciudad, pero obedeciendo a las órdenes del gobierno y, por otro, debería detener a los delincuentes al momento de cometer el delito, pero siempre atento a la justicia. Sin embargo, la inestabilidad política de 1815 obligó a suprimir la Intendencia y a fusionarla con el gobierno provincial hasta 1821(Galeano, 2009: 38, Vaccaroni, 2014).

4 Nos referimos a los instrumentistas y cantantes italianos arribados a partir de 1823 Angela Tani y Maria Tani (Hermanas a las que luego se sumarían Pascual, Francisco y Marcelo), a los matrimonios Cayetano Ricciolini e Isabel Ricciolini, Miguel Vacani y Maria Vacani, y a los músicos Santiago Massoni y Esteban Massini.

$\underline{5}$ Debido a la extensión y pertinencia del trabajo hemos omitido las referencias a los enfrentamientos judiciales en torno al teatro Coliseo Provisional. Sólo mencionaremos que hacia 1833 dos expedientes judiciales dan cuenta del enfrentamiento entre el asentista Olaguer Feliú contra Almagro, quien se enuncia como dueño del terreno y de la construcción y quien habría sido privado desde 1810 del acceso a su propiedad. La resolución final, expuesta en actas de policía obliga a que cualquier de las dos partes compre o venda su parte a fin de resolver el litigio.

$\underline{6}$ En 1804, luego de varios petitorios ante funcionarios del poder colonial, Ramón Aignase -dueño 
del terreno- y José Speciali -actor- inauguraron el teatro que, aunque tuvo la intención de superar al antiguo teatro llamado "La Ranchería" no dejó de tener un carácter provisional hasta su desaparición. (Trenti Rocamora, 1947). Respecto del derrotero del espacio en particular, sólo ha sido abordado por Beatriz Seigbel (2006) y el grupo GETEA (Pellettieri, 2005) previamente mencionado. Sin embargo es necesario advertir el predominio del relato acontecimental que solamente refiere a los estrenos de los diversos soportes teatrales y líricos, sin problematizar la relación entre la esfera política y los diversos grupos de particulares intervinientes en el teatro.

Z Respecto de la ausencia del Coliseo Provisional en el plan de reformas urbanas rivadavianas, también véase que es un espacio en el cual no se repara en el libro de Fernando Aliata (2006).

$\underline{8}$ Registro Oficial de la provincia de Buenos Aires. Libro 2, N 25. 6 de diciembre de 1822, pp. 425426.

$\underline{9}$ Registro Oficial de la provincia de Buenos Aires. Libro 2, N 25. 6 de diciembre de 1822, pp. 425426.

10 En este sentido, es necesario señalar que a inicios del siglo XIX la mayoría de teatros se caracterizaban por la inestabilidad económica. Particularmente, nos interesa resaltar que hasta en una ciudad virreinal desarrollada culturalmente como lo fue México durante el período tardocolonial, el teatro Coliseo Nuevo significó una pérdida constante (Viqueira Albán 1987: 59)

11 El Teatro de la Opinión, Buenos Aires, 6 de agosto de 1824, N 8. Tan sólo en 1825 El Argos manifestó la necesidad de realizar reformas materiales, llamando a licitación para su refacción externa. El Argos de Buenos Aires, Buenos Aires, 5 de enero de 1825, N 108. Tres años después de dichas críticas, The British Packet se refirió al estado material del teatro y señaló que "El interior es bastante aceptable y los últimos arreglos que se le han hecho lo han mejorado mucho. Pero el exterior es execrable” The British Packet, Buenos Aires, 12 de enero de 1828, N 75.

12 El concepto de asentista hace referencia al sujeto que alquilaba el teatro y que, durante un período determinado de meses, era el encargado de organizar la temporada musical y teatral.

13 Departamento General de Policía. Libro 9, N 68, 31 de marzo de 1824. Sala X, Legajo 32-10-4.

14 Departamento General de Policía. Libro 11, N 94, 15 de mayo de 1824. Sala X, Legajo 32-10-4.

15 El Teatro de la Opinión, Buenos Aires, 6 de agosto de 1824, N 8

$\underline{16}$ El Argos de Buenos Aires, Buenos Aires, No 62, 12 de agosto de 1824.

17 El Argos de Buenos Aires, Buenos Aires, 4 de Agosto de 1824, N 59.

18 Departamento General de Policía. Libro 9, N 104, 12 de Mayo de 1824. Sala X , Legajo 32-10-4.

19 Departamento General de Policía. Libro 12, N 177, con fecha de 18 de Julio de 1825. Sala X , Legajo 32-10-5. Se aclara que, tal como se dijo en el cuerpo del texto, la nota tiene fecha del 17 de septiembre de 1824.

20 Asimismo, la crónica Cinco años en Buenos Aires también refiere que en enero de 1825, luego de dos meses cerrado el teatro a causa de reformas edilicias, se había reabierto la temporada de ópera bajo la dirección de Rosquellas (Un inglés, 2002: 31) 
21 La Sociedad Filarmónica fue la primera asociación dedicada exclusivamente a lo musical. Si bien había iniciado sus reuniones en 1819 se inauguró oficialmente el 31 de Mayo de 1823. . Fue recién en dicho año cuando la Sociedad desarrolló sus conciertos de forma regular en un espacio material fijo y contó con un proyecto de reglamento sobre el cual asentar su dinámica y estrechó lazos con el gobierno al tiempo que impulsó una relativa autonomía de los músicos integrantes. En consonancia con la promoción de otros espacios asociativos, irrumpe la idea de que dichas instancias colaborarían a la construcción de nuevos vínculos interaccionales y costumbres modernas.

$\underline{22}$ Departamento General de Policía. Libro 12, N 165, 20 de Junio de 1825.Sala X , Legajo 32-105.

$\underline{23}$ Departamento General de Policía. Libro 19, N 105, 11 de abril de 1827. Sala X , Legajo 32-10-7.

24 Departamento General de Policía. Libro 9, n 104, 12 de mayo de 1824. Sala X, Legajo 32-10-4.

$\underline{25}$ Departamento General de Policía. Libro 12, N 177, 18 de Julio de 1825. Sala X, Legajo 32-10-5.

$\underline{26}$ En 1813 se inauguró el Real Teatro de Sao Joao, en homenaje el príncipe regente (Joao VI), quien a fin de impulsar la actividad lírica envió a buscar cantantes a Lisboa y castrati italianos. Sin embargo, recién en 1819, con la llegada de Pablo Rosquellas, Miguel Vacanni, Maria Teresa Fascioti, Justina, Carolina, Elisa y Fabricio Piaccentini, comenzaron a representarse con sistematización arias de óperas bufas. A pesar de esto, lejos de perdurar, la experiencia lírica en Río de Janeiro finalizó con el incendio del teatro en 1824. Si bien antiguos integrantes de la Compañía Nacional y de la Compañía Lírica Italiana formada se quedaron en Río, la mayoría de cantantes italianos decidió irse de la ciudad antes del incendio y probar suerte en Buenos Aires en 1823 (Vasco, 2008:44-50).

27 Departamento General de Policía. Libro 9 n 68, 31 de marzo de 1824. Sala X , Legajo 32-10-4.

$\underline{28}$ Departamento General de Policía. Libro 12, N 177, 18 de Julio de 1825. Sala X , Legajo 32-105.

29 Departamento General de Policía. Libro 10, n 121, 23 de Noviembre de 1824. Sala X , Legajo 32-10-4. También se adjunta una copia legalizada del Reglamento de la policía del teatro aprobada por el gobierno en Libro 10, n 122, 25 de noviembre de 1825.

30 Además de los enunciados aquí, el reglamento también hace referencia al acoso de cantantes tanto en los pasillos como en el propio escenario, la pelea entre hombres y el constante diálogo en voz alta en los palcos.

31 Departamento General de Policía. Libro 10, n 121, 23 de Noviembre de 1824. Sala X , Legajo 32-10-4.

32 A partir de 1815, dos años antes la conformación de la Sociedad del Buen Gusto por el Teatro, se comenzó a realizar un ordenado registro de cada función teatral en el cual se indicaban cantidad de entradas disponibles y vendidas, recursos comprados y artistas contratados. Asimismo, cada año se cerró con un libro titulado “deudores al teatro” en el cual se registran un promedio de cien nombres por año. De ello se infiere que la falta de pago del abono y las entradas era una práctica común. 
Véase AGN Sala X-43-08-05a.

$\underline{33}$ Departamento General de Policía. Libro 10, n 121, 23 de Noviembre de 1824. Sala X , Legajo 32-10-4.

34 También Mariano Bosch (1910: 45) al referirse a la división interna del teatro, aclara que la cazuela era un "verdadero gallinero y lugar de depravación donde se encerraba, como en corral, á todo un sexo, sin duda para que no molestara al otro (...)".

35 Departamento General de Policía. Libro 28, N 54, 13 de febrero de 1828. Sala X, Legajo 32-11-3

\section{Bibliografía}

Allier, R. (2008) ¿Qué es esto de la ópera? Introducción al mundo de la lírica. Barcelona: Robinbook: 2008.

Aliata, F. (2006) La ciudad regular. Arquitectura, programas e instituciones en el Buenos Aires posrevolucionario, 1821-1835. Buenos Aires: Prometeo.

Aspell, Marcela (1992) "El espejo de la vida" La regulación del teatro porteño en la primera mitad del siglo XIX”. En: Revista de Historia del Derecho, n 21, pp. 75-96.

Becker, H. (2008) Los mundos del arte. Sociología del trabajo artístico. UNQUI: Bernal.

Bosch, M. (1910) Historia del Teatro en Buenos Aires, Buenos Aires: Establecimiento tipográfico El Comercio.

Bruno, P. (2014) “Introducción. Sociabilidades y vida cultural en Buenos Aires, 1860-1930”, En: Bruno, Paula (Dir.) Sociabilidades y vida cultural en Buenos Aires, 1860-1930. Bernal: UNQUI.

Duhau E., Giglia A. (2008) Las reglas del desorden: habitar la metrópoli. México: Siglo XXI Editores-Universidad Autónoma Metropolitana, Unidad Azcapotzalco.

Galeano, D. (2009) Escritores, detectives y archivistas. La cultura policía en Buenos Aires. 18211910. Buenos Aires: Teseo.

Gallo, K. (2005) "Un escenario para la feliz experiencia. Teatro, política y vida pública en Buenos Aires. 1820-1827”. En: Batticuore, G., Gallo, K., Myers, J. (Comp.). Resonancias románticas: ensayos sobre historia de la cultura argentina, 1820- 1890 .Buenos Aires: Eudeba. Pp. 121-133.

Gayol, S. (2000) Sociabilidad en Buenos Aires: Hombres, honor y cafés 1862-1910. Buenos Aires, Ediciones del Signo.

Molina, E. (2004) “De recurso de pedagogía cívica a instrumento de disciplinamiento social: el espectáculo teatral en el programa reformista de la elite dirigente rioplatense (1810-1825)”. En: Prismas. Revista de historia intelectual, n 8, Pp. 33-58.

Myers, J. (2000) La revolución en las costumbres. Las nuevas formas de sociabilidad de la elite porteña, 1800-1860". En: Fernando Devoto; Marta Madero: Historia de la vida privada en la Argentina. Tomo I: País Antiguo. De la colonia a 1870. Buenos Aires: Taurus. 
Pelletieri, O. (Comp.) (2005) Historia del teatro en Buenos Aires. El período de la constitución (1770-1884). Buenos Aires: Galerna.

Rico, A. (2008) Policías, soldados, vecinos. Las funciones policiales entre las reformas rivadavianas y la caída del régimen rosista, Tesis de Maestría inédita, Universidad de Luján.

Seigbel, Beatriz (2006) Historia del Teatro Argentino. Desde los rituales hasta 1920. Buenos Aires: Corregidor.

Ternavasio, M., (2000) "Las reformas rivadavianas y el Congreso General Constituyente (18201827) Goldman, Noemí (Dir.) Nueva Historia Argentina. Revolución, República, Confederación, 1806-1852. Tomo III. Buenos Aires: Sudamericana.

Ternavasio, M., (2014) La revolución del voto. Prácticas y elecciones en Buenos Aires, 1810-1855. Buenos Aires: Siglo Veintiuno.

Un inglés (2002) Cinco años en Buenos Aires (1820-1825). Buenos Aires: Taurus.

Vaccaroni, Agustina (2014) “Las Órdenes Superiores: gobierno, policía y sectores subalternos” En: REFA, N 5, Pp. 141-151.

Vasco, M. (2008) A Música no Rio de Janeiro no Tempo de D. João VI. Río de Janeiro: Casa da Palabra.

Viqueira Albán, J. P. (1987) ¿Relajados o reprimidos? Diversiones públicas y vida social en la ciudad de México durante el Siglo de las Luces, México DF: Fondo de Cultura Económica.

Wilde, J.A. (1966) Buenos Aires desde Setenta Años Atrás, Buenos Aires: Eudeba. 